\title{
Setting handicaps to industrial sectors in DEA illustrated by Ethiopian industry
}

Kidanemariam Berhe Hailu

Kaoru Tone

May 2014

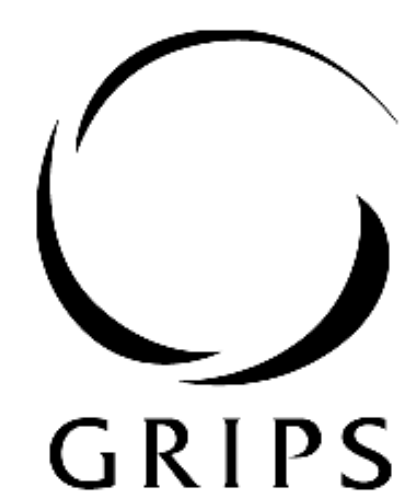

National Graduate institute FOR POLICY STUDIES

National Graduate Institute for Policy Studies

7-22-1 Roppongi, Minato-ku,

Tokyo, Japan 106-8677 


\title{
Setting handicaps to industrial sectors in DEA illustrated by Ethiopian industry
}

\author{
Kidanemariam Berhe Hailu \\ National Graduate Institute for Policy Studies, Japan \\ doc11102@grips.ac.jp \\ Kaoru Tone \\ National Graduate Institute for Policy Studies, Japan \\ tone@grips.ac.jp
}

\begin{abstract}
In the ordinary macro-economic input-output tables, the industrial sector consists of several dozen industries and each industry in a certain sector is an aggregate of many companies in the sector. The sectoral statistics are the sum of statistics of companies in the respective sector. Usually, all sectors have the same set of inputs for producing outputs. For example, they have labour, capital and intermediate as input and amount of production as output. We can apply traditional DEA models for evaluation of efficiency regarding all sectors by means of these common input and output factors. However, there remain some insecure feelings in comparing all sectors as a scratch race. Some sectors are in fields with matured technologies, while others are in emerging fields. Some are labour intensive, while others are capital intensive. These situations lead us to compare sectors under a handicap race. In this paper, we propose a new DEA
\end{abstract}


model based on the non-convex frontiers that all associated sectors may exhibit and handicaps are derived from. We apply this model to Ethiopian industry.

Keywords: Data envelopment analysis; non-convex frontier; handicap

\section{Introduction}

In the ordinary macro-economic input-output tables, the industrial sector consists of several dozen industries and each industry in a certain sector is an aggregate of many companies in the sector. The sectoral statistics are the sum of statistics of companies in the respective sector. Usually, all sectors have the same set of inputs for producing outputs. For example, they have labour, capital and intermediate as input and amount of production as output. We can apply traditional DEA models for evaluation of efficiency regarding all sectors by means of these common input and output factors. However, there remain some insecure feelings in comparing all sectors as a scratch race. Some sectors are in fields with matured technologies, while others are in emerging fields. Some are labour intensive, while others are capital intensive. These differences lead us to compare sectors under a handicap race. In this paper, we propose a new DEA model based on the non-convex frontiers that all associated sectors may exhibit and handicaps are derived from. Most DEA models assume convex set frontiers. However, there are non-convex frontiers as indicated by the S-shaped curves in production. Tone \& Tsutsui (2013) proposed a new DEA model that can cope with non-convex frontiers. They classify all DMUs (decision-making units) into several clusters and define a new efficiency score, called the $S A S$ (scale and cluster adjusted score), that can take into account non-convex frontiers. In this paper, we define the handicap of each industrial 
sector using the SAS model. We modify inputs (outputs) by the handicaps and re-evaluate the efficiency scores. We apply this model to Ethiopian industry.

Several authors have discussed handicap-related topics in DEA. Yang \& Paradi (2006) proposed a "Handicapped" Data Envelopment Analysis to Adjust for Corporate Strategic Effects for Canadian banks. They applied the index number originally proposed by Fixler \& Zieschang (1993). Their index number is based on the tactical and strategic heterogeneity between banks. Olsen \& Petersen (2009) discussed target and technical efficiency in DEA controlling for environmental characteristics. They extended Banker \& Morey (1986) and incorporated allowable handicap values into the model along the same lines as specifications of assurance regions in standard DEA.

Our problem and approach differ from the preceding ones as follows. (1) We deal with industrial sectors which have a two-layered structure, i.e., each sector consists of many companies in the sectoral category and its inputs/outputs are the sum of these companies. (2) Although we wish to evaluate technical efficiency of sectors, there are handicaps among sectors, as mentioned above, which should be identified and be accounted in efficiency measurement. (3) For this purpose, we first find the VRS frontiers of each sector and project companies in the sector to their frontiers. (4) Then, we find the VRS meta-frontiers regarding the projected companies in all sectors. (5) If the best performer (company) in a sector is positioned on the meta-frontiers, then we classify the sector as having no-handicap Otherwise, if the best performer is off the meta-frontiers, we classify the sector as with-handicap. This indicates that this sector is in either emerging fields or unfavourable environments. (6) In order to gauge the degree of handicaps, we apply a non-convex frontier model developed by Tone \& Tsutsui 
(2013) and decide the handicaps of with-handicap sectors. (7) Using handicaps, we adjust inputs (input-oriented case) and outputs (output-oriented case), and apply the CRS model to obtain the final sectoral efficiency score.

We would like to note that we are comparing sectoral efficiency as measured by the ratio input vs. output. For example, three sectors (food, textiles and motor) have the respective input (manpower) and output (profit) exhibited in Table 1. From this table, we see that the virtual (dual) value of input for Food is one tenth of that for Motor, but we do not intend to say that Food should reduce its input to 1, because the environments of three sectors are quite different. However, this kind of comparison is necessary and needed for understanding national and international economics.

Table 1: Three sectors

\begin{tabular}{|c|c|c|c|}
\hline Sector & Input (Manpower) & Output (Profit) & Output/Input \\
\hline Food & 10 & 1 & 0.1 \\
\hline Textiles & 5 & 1 & 0.2 \\
\hline Motor & 1 & 1 & 1 \\
\hline
\end{tabular}

This paper unfolds as follows: In Section 2 we introduce the basic framework and classify sectors into no-handicap and with-handicap groups. In Section 3 we set handicaps to with-handicap sectors. Then, we redefine sectoral inputs and outputs using the handicaps and obtain the final efficiency scores which take account of the sectoral handicaps in Section 4. In Section 5, we apply this model to Ethiopian industry. Section 6 concludes this paper.

\section{Basic framework}


In this section, we describe the basic materials in the paper.

Suppose that there are $K$ sectors in the industry and each sector $k(=1, \ldots, K)$ has $n_{k}$ DMUs with $m$ inputs and $s$ outputs. Let us denote a DMU in the sector $k$ by $\left(\mathbf{x}_{j}^{k}, \mathbf{y}_{j}^{k}\right)$ where $\mathbf{x}_{j}^{k} \in R_{+}^{m}\left(\mathbf{y}_{j}^{k} \in R_{+}^{s}\right)$ is the input (output) vector of the DMU. We define the set of DMUs in the sector $k$ by $\left(\mathbf{X}^{k}, \mathbf{Y}^{k}\right)$ with $\mathbf{X}^{k}=\left(\mathbf{x}_{1}^{k}, \ldots, \mathbf{x}_{n_{k}}^{k}\right)^{T}$ and $\mathbf{Y}^{k}=\left(\mathbf{y}_{1}^{k}, \ldots, \mathbf{y}_{n_{k}}^{k}\right)^{T}$.

\subsection{Evaluation of DMU within each sector and its projection onto frontiers of the sector}

We evaluate each DMU in its belonging sector by using the variable returns-to-scale (VRS) model. In this paper, we use the input oriented SBM (slacks-based measure (Tone 2001)). However other models, e.g. radial models, can be applied as well. This can be attained as below.

For each DMU $\left(\mathbf{x}_{o}^{k}, \mathbf{y}_{o}^{k}\right)\left(o=1, \ldots, n_{k}\right)$ we solve the following LP:

$$
\begin{aligned}
& \min _{\lambda, \mathbf{s}_{o}^{-}, s_{o}^{+}} 1-\frac{1}{m} \sum_{i=1}^{m} \frac{s_{i o}^{-}}{x_{i o}^{k}} \\
& \text { subject to } \\
& \mathbf{X}^{k} \boldsymbol{\lambda}+\mathbf{s}_{o}^{-}=\mathbf{x}_{o}^{k} \\
& \mathbf{Y}^{k} \boldsymbol{\lambda}-\mathbf{s}_{o}^{+}=\mathbf{y}_{o}^{k} \\
& \mathbf{e} \boldsymbol{\lambda}=1 \\
& \boldsymbol{\lambda} \geq \mathbf{0}, \mathbf{s}_{o}^{-} \geq \mathbf{0}, \mathbf{s}_{o}^{+} \geq \mathbf{0},
\end{aligned}
$$

where $\lambda$ is the intensity vector, and $\mathbf{s}_{o}^{-}$and $\mathbf{s}_{o}^{+}$are respectively input and output slacks.

Let an optimal solution to (1) be $\left(\lambda^{*}, \mathbf{s}_{o}^{-*}, \mathbf{s}_{o}^{+^{*}}\right)$. We project $\left(\mathbf{x}_{o}^{k}, \mathbf{y}_{o}^{k}\right)$ onto the efficient frontiers of sector $k$ as follows: 


$$
\overline{\mathbf{x}}_{o}^{k}=\mathbf{x}_{o}^{k}-\mathbf{s}_{o}^{-*}, \overline{\mathbf{y}}_{o}^{k}=\mathbf{y}_{o}^{k}+\mathbf{s}_{o}^{+*} .
$$

Thus, we obtain the set of DMUs $\left(\overline{\mathbf{x}}^{k}, \overline{\mathbf{Y}}^{k}\right)(k=1, \ldots, K)$ which are VRS-efficient with respect to the frontiers of sector $k$. See Figure 1.

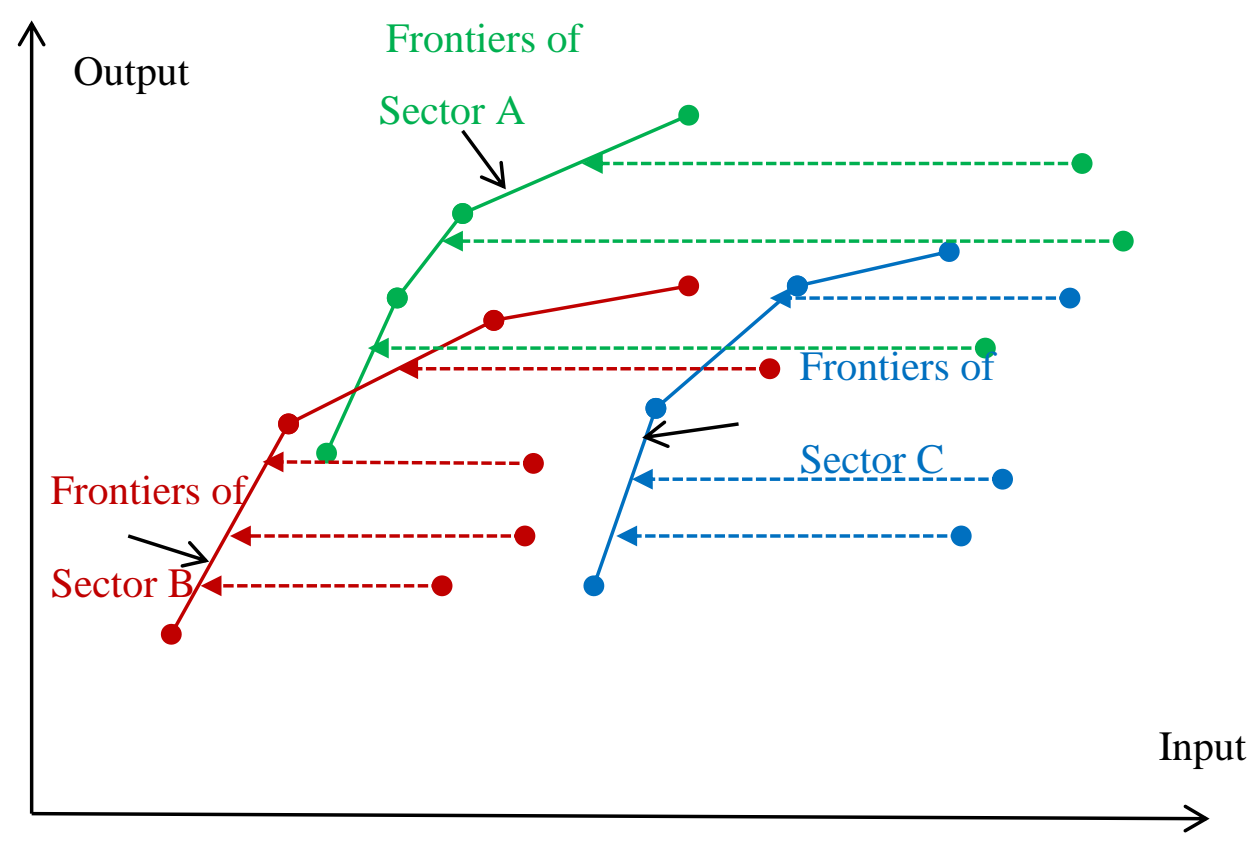

Figure 1: Sectoral frontiers and projections

\subsection{Global evaluation of the projected DMUs}

We merge the set $\left(\overline{\mathbf{X}}^{k}, \overline{\mathbf{Y}}^{k}\right)(k=1, \ldots, K)$ and denote it by $(\overline{\mathbf{X}}, \overline{\mathbf{Y}})$ which consists of $n_{1}+\cdots+n_{K}$ DMUs. We evaluate the VRS efficiency of $\left(\overline{\mathbf{x}}_{o}^{k}, \overline{\mathbf{y}}_{o}^{k}\right)$ with respect to $(\overline{\mathbf{X}}, \overline{\mathbf{Y}})$ 
and denote its VRS score by $\bar{\theta}_{o}^{k}$. Further, we define the maximum of $\bar{\theta}_{o}^{k}$ among sector $k$ as,

$$
\overline{\bar{\theta}}^{k}=\max _{o=1, \ldots, n_{k}}\left\{\bar{\theta}_{o}^{k}\right\}
$$

If $\overline{\bar{\theta}}^{k}=1$, the best performer of sector $k$ is located on the global VRS frontiers (meta-frontiers) of $(\overline{\mathbf{X}}, \overline{\mathbf{Y}})$. We judge that this sector $k$ has no handicap and classify $k$ to the no-handicap group. However, if $\overline{\bar{\theta}}^{k}<1$, the best performer of sector $k$ is inferior to the best performers in the no-handicap group, we classify $k$ to the with-handicap group. See Figure 2 where Sectors A and B belong to the no-handicap group and Sector $\mathrm{C}$ to the with-handicap group.

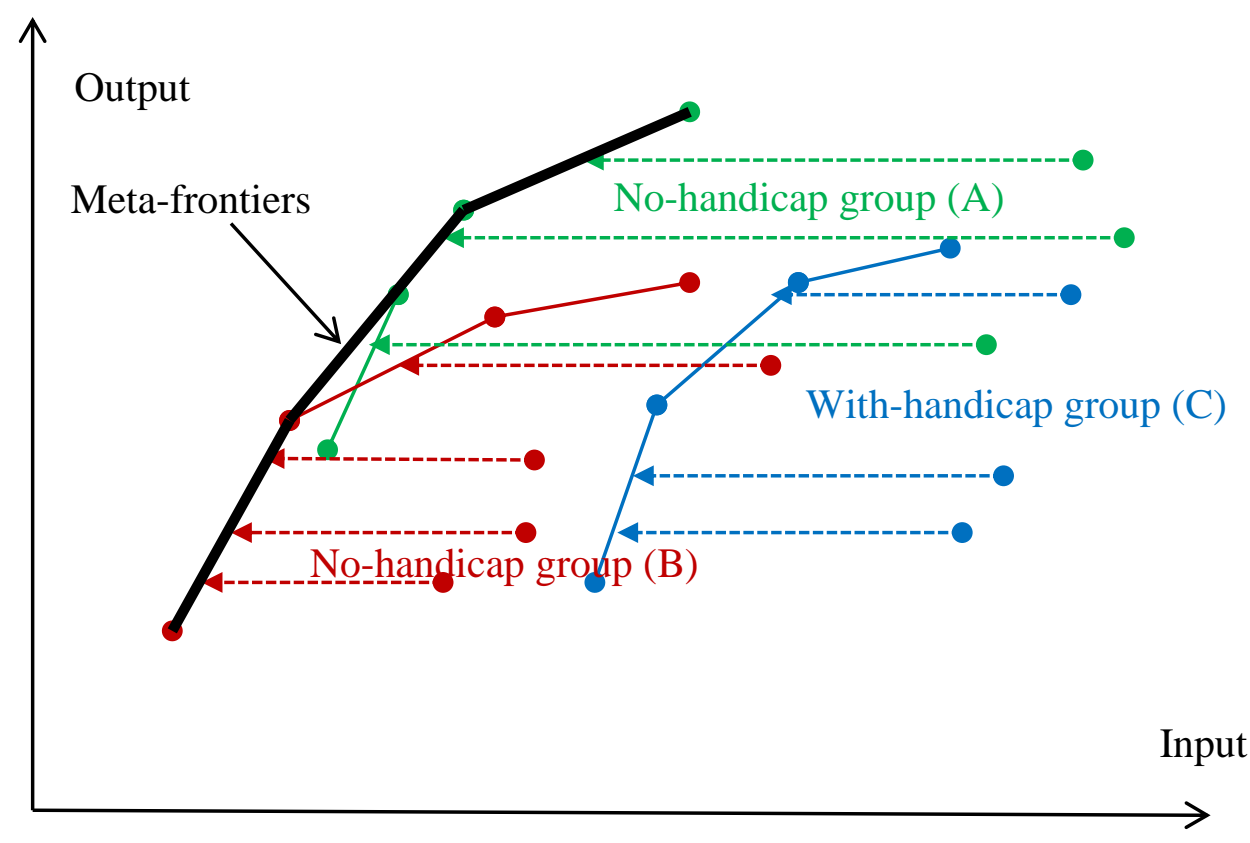

Figure 2: Meta-frontiers and handicaps 


\section{Handicaps}

In this section we describe the scheme how to set handicap to with-handicap group.

\subsection{Sectoral inputs and outputs}

Sectoral inputs and outputs can be defined as the aggregates of VRS-projected DMUs in the sector as follows:

$$
\begin{aligned}
& \text { Input to Sector } k: x_{i}^{k}=\sum_{j=1}^{n_{k}} x_{i j}^{k}(i=1, \ldots, m ; k=1, \ldots, K) \\
& \text { Output from Sector } k: y_{l}^{k}=\sum_{j=1}^{n_{k}}-y_{l j}^{k}(l=1, \ldots, s ; k=1, \ldots, K)
\end{aligned}
$$

Input/output vectors of sector $k$ are defined by

$$
\mathbf{x}^{k}=\left(x_{1}^{k}, \ldots, x_{m}^{k}\right)^{T} \text { and } \mathbf{y}^{k}=\left(y_{1}^{k}, \ldots, y_{s}^{k}\right)^{T}
$$

We deal with $K$ DMUs defined by $\left(\mathbf{x}^{k}, \mathbf{y}^{k}\right) \quad(k=1, \ldots, K)$.

\subsection{Clustering}

We classify $K$ sectors in several clusters. First, sectors belonging to no-handicap go to cluster "NHD", while sectors in with-handicap hold its sector name as the cluster name. For example, if a sector "Machinery and equipment" belongs to the with-handicap group, its cluster name is "Machinery and equipment".

The characteristics of industrial sectors are diverse. Some are in mature fields while others are in emerging fields. This suggests the existence of S-shaped (non-convex) frontiers as exhibited in Figure 3. Tone \& Tsutsui (2013) proposed a method for solving non-convex frontiers based on clusters. 


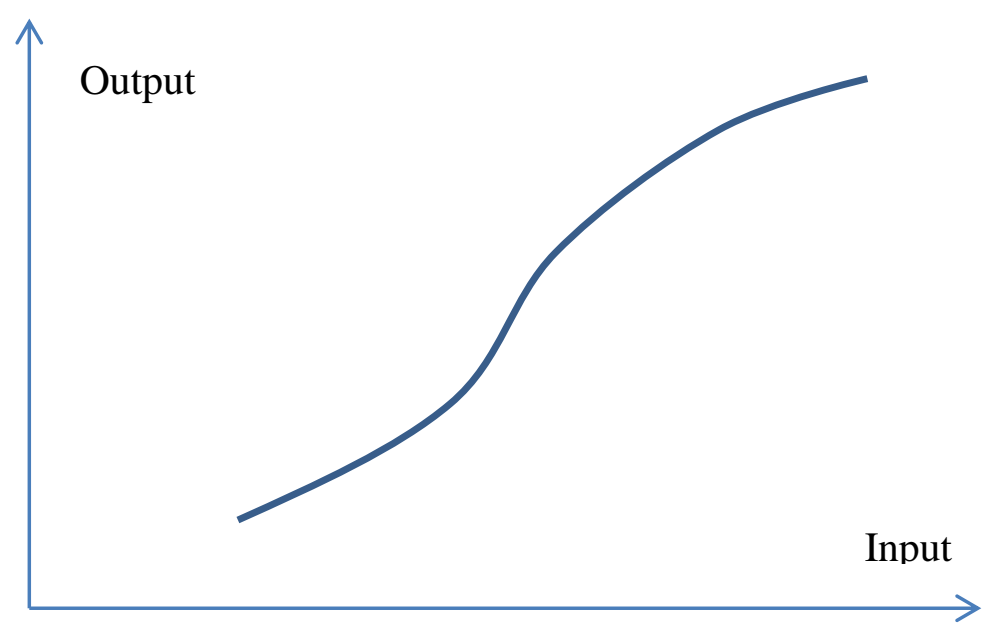

Figure 3: S-shaped frontier

\subsection{Solving the non-convex model}

We solve the dataset $\left(\mathbf{x}^{k}, \mathbf{y}^{k}\right)(k=1, \ldots, K)$ with cluster name using the above non-convex model and obtain the scale and cluster adjusted efficiency score, $S A S$, which takes into account the effect of non-convex frontiers.

\section{$3.4 \quad$ Handicap}

We define the handicap $h_{k}$ of sector $k$ as follows:

$h_{k}=1$, if the sector belongs to the no-handicap group.

$h_{k}=$ SAS score, if the sector belongs to the with-handicap group. 


\section{Global issues}

In this section, we redefine sectoral inputs and outputs using the above defined handicap and obtain the overall efficiency score of industries.

\subsection{Input (Output) under handicap}

In the input-oriented case, we define sectoral inputs and outputs as follows:

$$
\begin{aligned}
& \text { Sectorial input } \xi_{i}^{k}=h_{k} \sum_{j=1}^{n_{k}} x_{i j}^{k} \quad(i=1, \ldots, m: k=1, \ldots, K) \\
& \text { Sectorial output } \eta_{l}^{k}=\sum_{j=1}^{n_{k}} y_{l j}^{k} \quad(l=1, \ldots, s: k=1, \ldots, K)
\end{aligned}
$$

Further we define input/output vectors for each sector as follows:

$$
\xi_{k}=\left(\xi_{1}^{k}, \ldots, \xi_{m}^{k}\right)^{T} \text { and } \boldsymbol{\eta}_{k}=\left(\eta_{1}^{k}, \ldots, \eta_{s}^{k}\right)^{T} \quad(k=1, \ldots, K)
$$

See Figure 4 for an example.

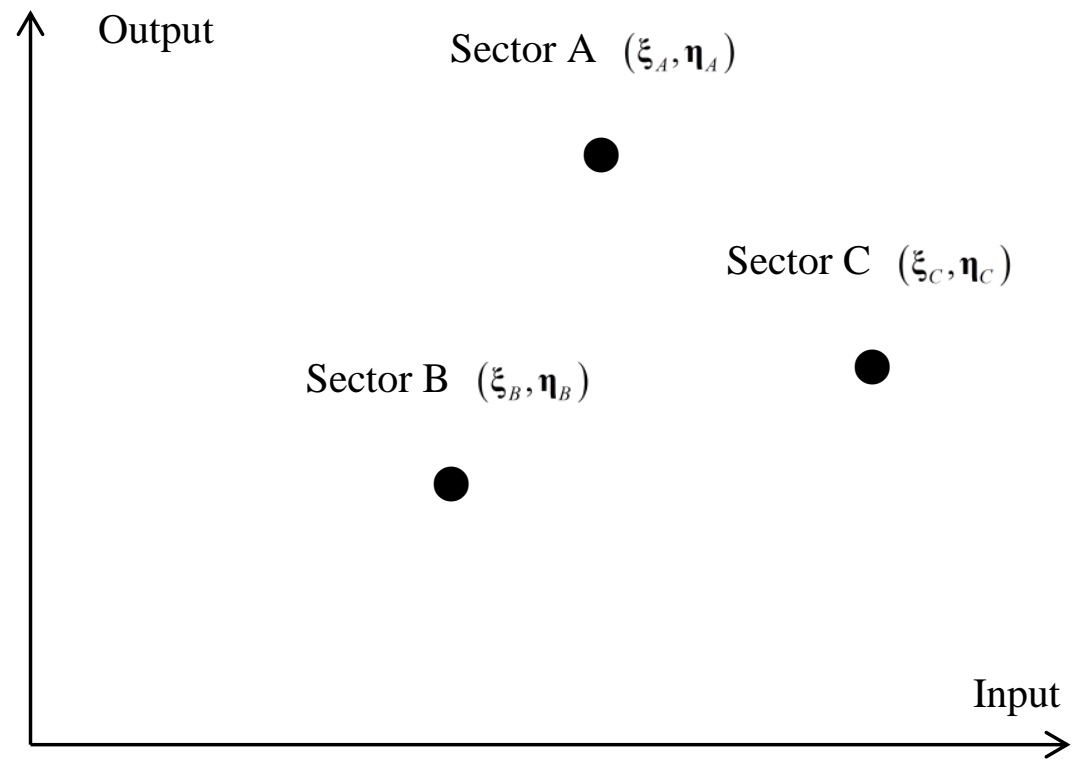

Figure 4: Handicapped input and output 


\subsection{Solving the CRS model}

In the non-radial SBM model case, we solve the following LP and obtain the sector-specific efficiency score $\theta_{o}^{*}(o=1, \ldots, K)$ under handicap.

$$
\begin{aligned}
& \theta_{o}^{*}=\min _{\lambda, s^{-}, s^{+}} 1-\frac{1}{m} \sum_{i=1}^{m} \frac{s_{i o}^{-}}{\xi_{i}^{o}} \\
& \text { st. } \\
& \sum_{k=1}^{K} \boldsymbol{\xi}_{k} \lambda_{k}+\mathbf{s}_{o}^{-}=\xi_{o} \\
& \sum_{k=1}^{K} \boldsymbol{\eta}_{k} \lambda_{k}-\mathbf{s}_{o}^{+}=\boldsymbol{\eta}_{o} \\
& \lambda \geq \mathbf{0}, \mathbf{s}_{o}^{-} \geq \mathbf{0}, \mathbf{s}_{o}^{+} \geq \mathbf{0}
\end{aligned}
$$

Let an optimal solution to (10) be $\left(\lambda^{*}, \mathbf{s}_{o}^{-*}, \mathbf{s}_{o}^{* *}\right)$. Then we have the projection to the SAS efficient frontiers as follows:

$$
\begin{aligned}
& \text { Projected input: } \boldsymbol{\xi}_{o}^{*}=\boldsymbol{\xi}_{o}-\mathbf{s}_{o}^{\mathbf{s}^{*}} \\
& \text { Projected output: } \boldsymbol{\eta}_{o}^{*}=\boldsymbol{\eta}_{o}+\mathbf{s}_{o}^{\mathbf{+}^{*}} .
\end{aligned}
$$

\section{Application to Ethiopian industry}

In this section, we describe the characteristics of the manufacturing sector and our data, and apply our model to 14 industrial groups which largely dominate the Ethiopian manufacturing sector.

\subsection{On Ethiopian industry}

\subsubsection{The manufacturing sector}

Ethiopia's industrial sector has not yet taken off. Its contribution to GDP has been stagnating for long periods of time, amounting to between 13 and 14 percent. Particularly, the share of the manufacturing sub-sector remained stagnant. The 
manufacturing sector is dominated by simple agro-processing activities and production of basic consumer goods. All manufacturing exports are agriculture-based, which include clothing, semi-processed hides, footwear, beverages and others. However, Ethiopia has great potential to jump-start its manufacturing sector. Ethiopia has abundant low-cost labour, which gives it a comparative advantage in less-skilled, labour-intensive sectors such as light manufacturing which includes textile, wood products, leather products and apparel industries (Dinh et al., 2012; Sonobe, 2009). This provides a good opportunity for low-cost manufacturing exports. Moreover, Ethiopia has abundant natural resources including cattle, which can be used as an input for making leather and leather products; forests, which can be used in the furniture industry; cotton, which can be expanded to further develop the garments industry; and land for the agribusiness industry. On the policy side, the government, with an aim of transforming the country from agrarian to industrialised nation, has been preparing an environment conducive to attracting direct foreign investment and domestic investment. To tap into all of these opportunities, many foreign companies including those from China, India, Japan and Turkey are currently flocking into the country.

\subsubsection{The data}

The data used in this application was extracted from the Central Statistical Agency (CSA) of Ethiopia database. CSA conducts annual census (covering the entire population) of large and medium sized power driven manufacturing firms of the country that employ 10 persons or more. We use data from the 2008 census that comprises relevant outputs and inputs. Based on the literature and data availability, we use a single-output and 3-input production technology for Ethiopian manufacturing. Output is 
measured by the gross value of all outputs produced by the firm. The inputs include: (i) the number of employees measured by the sum of permanent and temporary workers, (ii) capital input measured by the net value of fixed assets at the end of the survey year, (iii) intermediate inputs aggregated as the sum of the values of raw materials, fuel and lubricating oil, electricity, wood and charcoal for energy for each establishment and other industrial costs. The types of industries for which our model applies include manufacture of: (1) Food and beverage, (2) Textiles, (3) Wearing apparel, (4) Tanning, leather and footwear, (5) Wood and wood products, (6) Paper and printing, (7) Chemical and chemical products, (8) Rubber and plastics products, (9) Non-metallic mineral products, (10) Fabricated metal products (11) Basic iron and steel, (12) Machinery and equipment, (13) Motor vehicles and (14) Furniture.

For the purpose of this application, the firm level data were aggregated to 2-digit level industries according to the "International Standard Industrial Classification of All Economic Activities" (ISIC). Prior to data aggregation, we have made super-efficiency procedures to detect outliers in the data. According to the findings, three firms with super-efficiency greater than or equal to three were found as outliers and we deleted them from the data leaving the total of firms from which data was aggregated to industry level 11,213. Moreover, since inflation in 2008 was at its peak in Ethiopia, the data was adjusted for price changes. All inputs (except labour) and output were deflated 
by their respective sectoral price deflator taking year 2000 as the base year. Finally, to avoid data fluctuations, we also smooth the data using a four-year moving average ${ }^{1}$.

\subsection{Main statistics}

We begin by presenting the original (non-handicapped) dataset in Table 2. The summary statistics of this dataset is exhibited in Table 3. The summary statistics in Table 3 represent the Min/Max inputs and output of the industry.

Table 2: Original dataset for the year $2008^{2}$

\begin{tabular}{lccccc}
\hline \multicolumn{1}{c}{ Industry } & Companies & (I)Labour & (I)Capital & (I)Intermediate & (O)Production \\
\hline Food and beverage & 349 & 35391.1458 & 1788168221 & 1495232246 & 4068003497 \\
Textiles & 21 & 18363.7916 & 381057469 & 395188377 & 692187774 \\
Wearing apparel & 26 & 4815.79165 & 104353732 & 65318032.1 & 129750825 \\
Tanning, leather \&footwear & 62 & 7887.5625 & 363361747 & 561064968 & 890647967 \\
wood & 28 & 1959.81248 & 6871141.31 & 20176600.1 & 56729660.1 \\
Paper and printing & 96 & 7967.64585 & 180550018 & 320157164 & 638558017 \\
Chemicals & 61 & 6426.50001 & 286834161 & 482231522 & 818780598 \\
Rubber and plastics & 75 & 7083.16665 & 361385672 & 417657829 & 727078679 \\
Non-metals & 243 & 10300.75 & 677356667 & 576183151 & 1377392696 \\
Basic iron and steel & 14 & 1821.60418 & 212223001 & 633340164 & 1002609408 \\
Fabricated metals & 49 & 2482.89584 & 88309646.7 & 189549991 & 342615766 \\
Machinery and equipment & 9 & 1303.5 & 92018536.2 & 67075028.3 & 116429874 \\
Motor vehicles & 10 & 1214.41666 & 60968765.8 & 233431786 & 327031850 \\
Furniture & 170 & 4529.18749 & 93204031.8 & 87966624.3 & 189933023 \\
\hline
\end{tabular}

1 The 2008 data is part of the big dataset (covering 2000 to 2009) we had. We first made a four-year moving average adjustment using the 2000 to 2009 dataset and then extracted the 2008 data for the purpose of this application.

2 "I" and "O" stand for input and output, respectively. The value of capital, intermediate inputs and output are measured in Ethiopian Birr (ETB), Ethiopia's currency. The current exchange rate of ETB against USD is about Birr 19.41 to 1 USD. Labour is measured by the number of annual temporary and permanent workers. Moreover, to consider price changes in our study, inputs (except labour) and output were deflated by their respective implicit sectoral GDP deflator at 2000 price. 
Table 3: Industry level summary statistics (non-handicapped data)

\begin{tabular}{lcccc}
\hline Statistics & (I)Labour & (I)Capital & (I)Intermediate & (O)Production \\
\hline Minimum & 1214.417 & 6871141.31 & 20176600.1 & 56729660.1 \\
Average & 7967.698 & 335475915 & 396040963 & 812696402 \\
St. Dev. & 9133.455 & 454726832 & 378329529 & 1014420298 \\
Maximum & 35391.15 & 1788168221 & 1495232246 & 4068003497 \\
\hline
\end{tabular}

\subsection{Evaluation of DMU within each sector and projection}

Utilising the scheme described in Section 2.1, we evaluate each DMU in their respective industry to obtain sectoral frontiers and projections. To this end, we use the VRS input oriented SBM. The development of the handicap model begins with the utilisation of the projected inputs and output where all the DMUs are on their efficient frontier in their respective industry. In Table 4, we provide the industry level summary statistics of the projected inputs and output.

Table 4: Industry level summary statistics of the projected data

\begin{tabular}{lcccc}
\hline Statistics & (I)Labour & (I)Capital & (I)Intermediate & (O)Production \\
\hline Minimum & 942.0572 & 3140337.5 & 18952775 & 57420822.6 \\
Average & 4461.147 & 158798402 & 285544233 & 871889484 \\
St. Dev. & 4508.271 & 226084166 & 219213081 & 1150917694 \\
Maximum & 18689.76 & 870850327 & 821789723 & 4544356485 \\
\hline
\end{tabular}

\subsection{Global evaluation of the projected DMUs}

The efficiency scores in Table 5 were calculated according to the procedure outlined in Section 2.2. After merging the projected inputs and output, we evaluated DMUs with the VRS model from which the maximum score $\overline{\bar{\theta}}^{k}$ of DMUs in their respective sector was defined to judge whether the industry belongs to the no-handicap group or 
with-handicap group. Accordingly, we see in Table 5 that Wearing apparel, Tanning, Leather and footwear, Paper and printing, and Machinery and equipment industries are in the with-handicap group while the remaining industries are in the no-handicap group.

We also exhibit inputs and output of a sample company with the maximum score $\overline{\bar{\theta}}^{k}$ for each industry. An industry with $\overline{\bar{\theta}}^{k}=1$ belongs to the meta-frontiers.

Table 5: No-handicap group and with-handicap group before non-convex adjustment

\begin{tabular}{|c|c|c|c|c|c|c|c|}
\hline \multirow[b]{2}{*}{ Industry } & \multirow{2}{*}{$\overline{\bar{\theta}}^{k}$} & \multirow{2}{*}{$=\max _{0=1, \ldots, n_{k}}\left\{\bar{\theta}_{0}^{k}\right\}$} & \multicolumn{4}{|c|}{ A sample company with $\max \theta$} & \multirow[b]{2}{*}{ Meta-frontier $(\mathrm{Y} / \mathrm{N})^{3}$} \\
\hline & & & (I)Labour & (I)Capital & (I)Intermediate & (O)Output & \\
\hline Food and beverage & & 1 & 12.35922 & 140318.8 & 177992.6516 & 8041129 & Y \\
\hline Textiles & & 1 & 1725 & 32069.7 & 21700000 & 37900000 & Y \\
\hline Wearing apparel & & 0.343418 & 13.16667 & 4321.956 & 66919.76 & 87352.65 & $\mathrm{~N}$ \\
\hline Tanning, leather and footwear & & 0.909345 & 10.5 & 1823.441 & 12303.54 & 60075.27 & $\mathrm{~N}$ \\
\hline Wood & & 1 & 40 & 2111.534 & 205487.8 & 1042979 & $\mathrm{Y}$ \\
\hline Paper and printing & & 0.488351 & 12 & 3216.459 & 43311.45 & 97698.5 & $\mathrm{~N}$ \\
\hline Chemicals & & 1 & 21.23822 & 435970.9 & 2246884.544 & 6319859 & $\mathrm{Y}$ \\
\hline Rubber and plastics & & 1 & 62 & 6717595 & 1254564 & 74600000 & $\mathrm{Y}$ \\
\hline Not-metals & & 1 & 91.58334 & 170206.5 & 6084128 & 18100000 & $\mathrm{Y}$ \\
\hline Fabricated metals & & 1 & 19 & 832519.9 & 26876.57 & 2437786 & $\mathrm{Y}$ \\
\hline Basic iron and steel & & 1 & 290 & 2863552 & 102000000 & 182000000 & Y \\
\hline Machinery and equipment & & 0.447216 & 177.0833 & 3709670 & 27800000 & 48100000 & $\mathrm{~N}$ \\
\hline Motor vehicle & & 1 & 148 & 6583011 & 177000000 & 217000000 & $\mathrm{Y}$ \\
\hline Furniture & & 1 & 12.33333 & 36995.28 & 2078167 & 5568806 & Y \\
\hline
\end{tabular}

\subsection{Handicaps}

${ }^{3}$ While "Y" indicates the sector is on the Meta-frontier (belonging to the no-handicap group), "N" implies the sector is off the Meta-frontier (belonging to the with-handicap group). 


\subsubsection{Sectoral inputs and outputs}

Table 6 presents sectoral inputs and outputs aggregated from the VRS-projected DMUs in the sector according to Section 3.1.

Table 6: Aggregates of inputs (output) of VRS-projected DMUs in the sector

\begin{tabular}{lcccc}
\hline \multicolumn{1}{c}{ Industry } & (I)Labour & (I)Capital & (I)Intermediate & (O)Production \\
\hline Food and beverage & 18689.76 & 870850327 & 821789723 & 4544356485 \\
Textiles & 5477.866 & 37291624 & 191300303 & 363220956 \\
Wearing apparel & 5713.199 & 139074482 & 112307222 & 220631685 \\
Tanning, leather and footwear & 5005.315 & 186313400 & 469860107 & 800649505 \\
Wood & 2325.809 & 3140337.5 & 18952775 & 57420822.6 \\
Paper and printing & 5693.758 & 88431187 & 267162146 & 614123385 \\
Chemicals & 2788.107 & 82517926 & 442951464 & 1028226007 \\
Rubber and plastics & 2374.122 & 174408612 & 174512573 & 956744221 \\
Not-metals & 6230.622 & 379273000 & 490968503 & 1782276024 \\
Fabricated metals & 2052.191 & 74160812 & 223054964 & 460355315 \\
Basic iron and steel & 942.0572 & 46086368 & 392698767 & 659006974 \\
Machinery and equipment & 1046.282 & 60668080 & 59152487 & 114955660 \\
Motor vehicle & 1313.834 & 50655770 & 262797476 & 397401292 \\
Furniture & 2803.14 & 30305709 & 70110758 & 207084441 \\
\hline
\end{tabular}

\subsubsection{Solving non-convex models}

Here, we solve the non-convex nature of the data using the data in Table 6 and classify the scale adjusted scores (SAS) of each sector. In Table 7 "a" stands for non-handicapped group. We found that all with-handicap sectors belong to non-convex (S-shaped) frontiers.

Table 7: No-handicap group and with-handicap group after non-convex adjustment

\begin{tabular}{lllllll}
\hline \multicolumn{1}{c}{ Industry } & (I)Labour & (I)Capital & (I)Intermediate & (O)Production & Cluster & SAS \\
\hline Food and beverage & 18689.8 & 870850327 & 821789723 & 4544356485 & $\mathrm{a}$ & 1 \\
Textiles & 5477.87 & 37291624 & 191300303 & 363220956 & $\mathrm{a}$ & 0.5931 \\
Wearing apparel & 5713.2 & 139074482 & 112307222 & 220631685 & Wearing apparel & 0.768
\end{tabular}


Tanning, leather and

Tanning, leather and

\begin{tabular}{|c|c|c|c|c|c|c|}
\hline footwear & 5005.31 & 186313400 & 469860107 & 800649505 & footwear & 0.9923 \\
\hline Wood & 2325.81 & 3140337.5 & 18952775 & 57420822.6 & $\mathrm{a}$ & 1 \\
\hline Paper and printing & 5693.76 & 88431187 & 267162146 & 614123385 & Paper and printing & 0.9715 \\
\hline Chemicals & 2788.11 & 82517926 & 442951464 & 1028226007 & a & 1 \\
\hline Rubber and plastics & 2374.12 & 174408612 & 174512573 & 956744221 & $\mathrm{a}$ & 1 \\
\hline Not-metals & 6230.62 & 379273000 & 490968503 & 1782276024 & $\mathrm{a}$ & 0.7429 \\
\hline Fabricated metals & 2052.19 & 74160812 & 223054964 & 460355315 & $\mathrm{a}$ & 0.664 \\
\hline Basic iron and steel & 942.057 & 46086368 & 392698767 & 659006974 & a & 1 \\
\hline Machinery and & & & & & Machinery and & \\
\hline equipment & 1046.28 & 60668080 & 59152487 & 114955660 & equipment & 0.5433 \\
\hline Motor vehicle & 1313.83 & 50655770 & 262797476 & 397401292 & $\mathrm{a}$ & 0.6274 \\
\hline Furniture & 2803.14 & 30305709 & 70110758 & 207084441 & $\mathrm{a}$ & 0.6622 \\
\hline
\end{tabular}

\subsubsection{Handicap}

The final (after non-convex adjustment) handicap scores are reported in Table 8 .

Table 8: Handicap score after non-convex adjustment

\begin{tabular}{lc}
\hline \multicolumn{1}{c}{ Industry } & Handicap \\
\hline Food and beverage & 1 \\
Textiles & 1 \\
Wearing apparel & 0.768 \\
Tanning, leather and footwear & 0.9923 \\
Wood & 1 \\
Paper and printing & 0.9715 \\
Chemicals & 1 \\
Rubber and plastics & 1 \\
Not-metals & 1 \\
Fabricated metals & 1 \\
Basic iron and steel & 1 \\
Machinery and equipment & 0.5433 \\
Motor vehicle & 1 \\
Furniture & 1 \\
\hline
\end{tabular}




\subsection{Global issue}

\subsubsection{Input (output) under handicap}

In this section, we apply the scheme outlined in Section 4.1 to obtain the handicapped data. Since we are using the input-oriented model, the inputs of the original dataset of each sector were multiplied by the handicap scores given in Table 8 to arrive at the data in Table 9.

Table 9: Handicapped Inputs and output

\begin{tabular}{lcccc}
\hline \multicolumn{1}{c}{ Industry } & (I)Labour & (I)Capital & (I)Intermediate & (O)Production \\
\hline Food and beverage & 35391.15 & 1788168221 & 1495232246 & 4068003497 \\
Textiles & 18363.79 & 381057469 & 395188377 & 692187774 \\
Wearing apparel & 3698.528 & 80143666.2 & 50164248.7 & 129750825 \\
Tanning, leather and footwear & 7826.828 & 360563862 & 556744768 & 890647967 \\
Wood & 1959.812 & 6871141.31 & 20176600.1 & 56729660.1 \\
Paper and printing & 7740.568 & 175404343 & 311032684 & 638558017 \\
Chemicals & 6426.5 & 286834161 & 482231522 & 818780598 \\
Rubber and plastics & 7083.167 & 361385672 & 417657829 & 727078679 \\
Not-metals & 10300.75 & 677356667 & 576183151 & 1377392696 \\
Fabricated metals & 1821.604 & 212223001 & 633340164 & 1002609408 \\
Basic iron and steel & 2482.896 & 88309646.7 & 189549991 & 342615766 \\
Machinery and equipment & 708.1915 & 49993670.7 & 36441862.9 & 116429874 \\
Motor vehicle & 1214.417 & 60968765.8 & 233431786 & 327031850 \\
Furniture & 4529.187 & 93204031.8 & 87966624.3 & 189933023 \\
\hline
\end{tabular}

\subsubsection{Solving the CRS model}

So far, we have been adjusting the original data in order to account for the handicap industry. In Table 10, we report the efficiency scores of each industry obtained after 
making handicap adjustments. To obtain the efficiency scores reported in Table 10, we used the dataset given in Table 9 .

Table 10: Efficiency score with handicap model

\begin{tabular}{lrc}
\hline \multicolumn{1}{c}{ Industry } & Score & Rank \\
\hline Food and beverage & 0.8357 & 6 \\
Textiles & 0.5192 & 14 \\
Wearing apparel & 0.5727 & 13 \\
Tanning, leather and footwear & 0.5836 & 12 \\
Wood & 1 & 1 \\
Paper and printing & 0.8722 & 5 \\
Chemicals & 0.6640 & 9 \\
Rubber and plastics & 0.5899 & 11 \\
Non-metals & 0.7839 & 8 \\
Fabricated metals & 1 & 1 \\
Basic iron and steel & 0.834 & 7 \\
Machinery and equipment & 1 & 1 \\
Motor vehicle & 1 & 1 \\
Furniture & 0.6019 & 10 \\
\hline
\end{tabular}

\subsubsection{Comparisons with no-handicap model}

The scores in Table 11 were obtained using the original (non-handicapped) dataset reported in Table 2. Figure 5 compares the scores from the no-handicap and with-handicap models where the heading $(\mathrm{H})$ indicates the with-handicap sector.

Table 11: Efficiency sore with no-handicap model

\begin{tabular}{ccc}
\hline Industry & Score & Rank \\
\hline Food and beverage & 1 & 1
\end{tabular}




\begin{tabular}{lcc} 
Textiles & 0.5359 & 13 \\
Wearing apparel & 0.5037 & 14 \\
Tanning, leather and footwear & 0.5776 & 11 \\
Wood & 1 & 1 \\
Paper and printing & 0.8918 & 7 \\
Chemicals & 0.6943 & 8 \\
Rubber and plastics & 0.6216 & 10 \\
Non-metals & 0.9304 & 5 \\
Fabricated metals & 1 & 1 \\
Basic iron and steel & 0.9215 & 6 \\
Machinery and equipment & 0.5401 & 12 \\
Motor vehicle & 1 & 1 \\
Furniture & 0.6627 & 9 \\
\hline
\end{tabular}

\subsection{Observations}

In Figure 5, we see that of the 3 handicapped industries, Wearing apparel, Tanning, and Machinery and equipment have seen improvements in efficiency after handicap adjustment was made, with Machinery and equipment industry becoming efficient. There is a slight decline in efficiency score in the Paper and printing industry (handicapped) and the no-handicap industries as compared to no-handicap model. The decrease of efficiency scores in Paper and printing and other sectors might have been caused by the increase of Machinery and equipment score (it has the smallest handicap and is efficient now). The emergence of this efficient sector affects all other sectors.

In this application, we tried to standardize different industries of different nature which use different inputs to produce different outputs. However, we believe that the 
model can also be applied to sectors (DMUs) in the same industry such as banks and electric power industry. Given that these industries provide similar services to their respective customers, the only difference remains the environment in which they operate. Some of the DMUs may enjoy advantages such as location and infrastructure while others do not. Unlike the traditional DEA which assumes DMUs enjoy similar environment, our model takes these environmental differences into account. Moreover, we can even make regional and/or international comparisons of DMUs producing similar products but they differ only in their environmental set up.

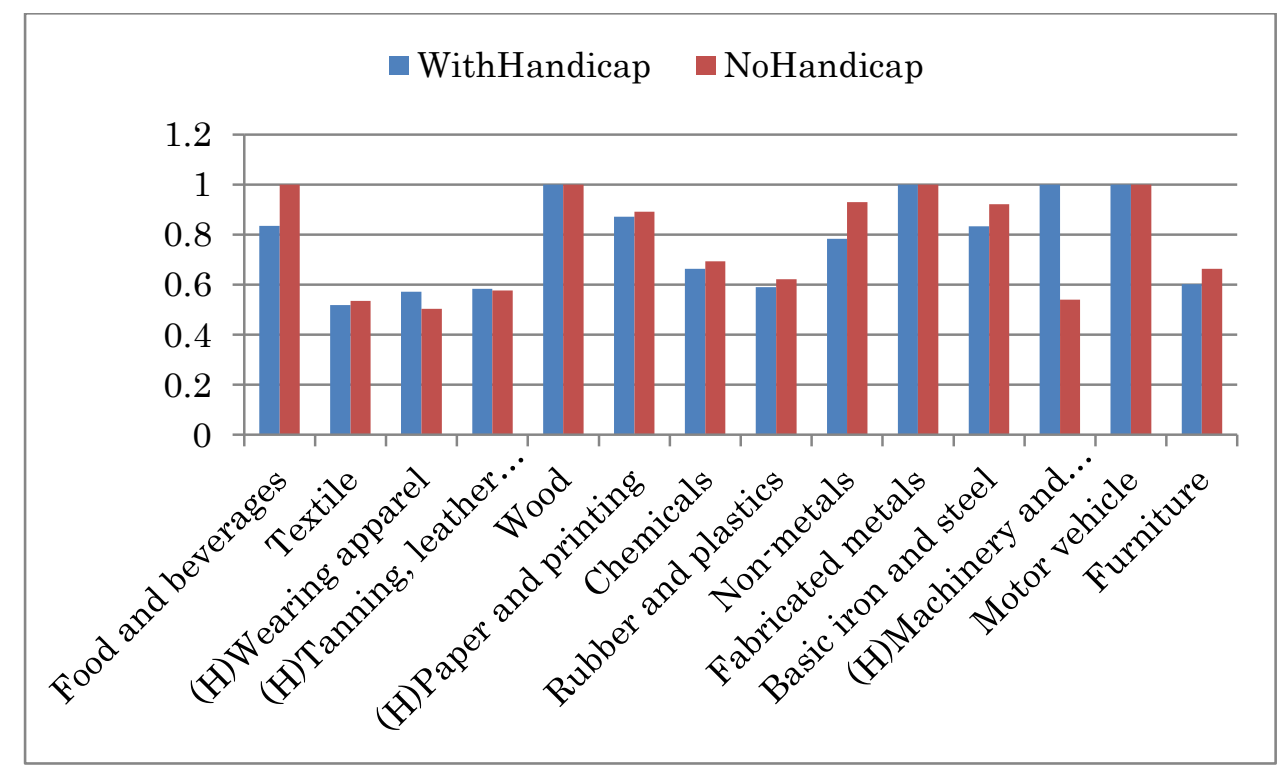

Figure 5: Comparison of handicap and no-handicap models

\subsection{Policy implications}

Besides the contribution of this study to handicap modelling in DEA, its application to Ethiopian industrial sector has certain policy implications. From policy perspective, the study of efficiency in the industrial sector may be helpful to allocate resources in a more efficient and productive way. This study can also be used as an input for policy 
makers to formulate policies that are sector specific by identifying the best and worst performing industries. For instance, despite the strong belief that Ethiopia can be an industrial hub in labour-intensive light manufacturing such as Textiles, Wearing apparel, Tanning, leather and leather products and Furniture industries, the performance of these sectors remained poor in the period under study. While we suggest that concerned bodies should take further studies to investigate as to why low performance is registered in these sectors, it is also possible to cite factors such as poor input supply chain, lack of international exposure and poor technology might have contributed to the poor performance of the mentioned sectors.

For instance, it is often reported that there is difficulty in accessing quality hides and skins that would be used in the Leather and leather products industry. Hence, given that Ethiopia has a comparative advantage in providing ample inputs to boost these sectors, we suggest that the government needs to engage itself in reforming the input industries to achieve maximum efficiency in the sectors. We suggest that the government should introduce proper incentives in the input market. Provision of marketing information and marketing channels should be encouraged. As Ethiopian domestic investors are less competitive in the international arena, foreign direct investment may be helpful in bringing international experience, thereby improving the efficiency and competiveness of the sectors. The poor performance of the sectors might also indicate that firms in these sectors are using some older techniques of production (outdated machinery) in the production process. Hence, improving the existing techniques of production and/or introduction of modern machineries may improve the efficiency level. The Machinery 
and equipment sector, in particular, has the potential to be the top industry, if innovation in inputs were executed.

\section{Conclusions}

In this paper, we proposed a handicap setting method for fair evaluation of industrial sectors and applied it to Ethiopian industry. The Manufacturing industry comprises many sectors which include many companies in the category. Thus, there is a "two-layered" structure. The statistics of a sector is the sum of those of its member companies. In order to evaluate the relative efficiency of industrial sectors, we need to take account of performance of their membership companies. For this purpose, we evaluated sectoral frontiers and projected member companies to their respective frontiers. We then merged the projected companies and found the meta-frontiers of all projected companies in the industry. If a member of a certain sector is on the meta-frontiers, we classified this sector to the no-handicap group, whereas if all members of a sector are off the meta-frontier, we classified the sector to the with-handicap group. Then we applied the non-convex model proposed in Tone \& Tsutsui (2013) for deciding handicaps of with-handicap sectors. Actually, most of them belong to no-convex (S-shaped) frontiers. We modify inputs (in the input-oriented case) or outputs (in the output-oriented case) using the handicaps and re-evaluate the sectoral efficiency. As for the developing industry of Ethiopia, several sectors are in emerging fields. We found four sectors belonged to the with-handicap group; (1) Wearing apparel (handicap=0.768), (2) Tanning, leather and footwear (handicap=0.9923), (3) Paper and printing (handicap=0.9715), and (4) Machinery and equipment (handicap=0.5433). The most handicapped one is the Machinery and equipment sector. If this sector was 
improved by innovation, it would become the top sector, while the other three handicapped sectors remain inefficient even after taking account of handicaps. The sectors in the no-handicap group could not increase the relative efficiency. This might be caused by the emergence of the Machinery and equipment sector as the efficient one.

Further research subjects include cost, revenue and profit-related extensions of this approach.

\section{References}

Banker, R.D., \& Morey, R.C. (1986). Efficiency Analysis for Exogenously Fixed Inputs and Outputs. Operations Research, 34(4), 513-521.

Dinh, H., Palmade, V., Chandra, V., \& Cossar, F. (2012). Light Manufacturing in Africa:Light Manufacturing Private Investment and Create Job. World Bank.

Fixler, D.J., \& Zieschang, K.D. (1993). An Index Number Approach to Measuring Bank Efficiency: an Application to Mergers. Journal of Banking and Finance, 17, 99437-99450.

Olsen, O.B., Petersen, N.C. (2009). Target and Technical Efficiency in DEA: Controlling for Environmental Characteristics. Journal of Productivity Analysis, $32,27-40$.

Sonobe, T., Akoten, J., \& Otsuka, K. (2009). An Exploration into the Successful Development of the Leather-Shoe Industry in Ethiopia. Review of Development Economics, 13(4), 719-736.

Tone, K. (2001). A Slacks-based Measure of Efficiency in Data Envelopment Analysis. European Journal of Operational Research, 130, 498-509.

Tone, K., \& Tsutsui, M. (2013). How to Deal with S-shaped Curve in DEA. GRIPS Report 13-10. http://r-center.grips.ac.jp/gallery/docs/13-10.pdf. 
Yang, Z. \& Paradi, J.C. (2006). Cross Firm Bank Branch Benchmarking Using "Handicapped" Data Envelopment Analysis to Adjust for Corporate Strategic Effects. Proceedings of the $39^{\text {th }}$ Hawaii International Conference on System Sciences, 1-10. 